\title{
FIBROIDS IN PREGNANCY; OBSTETRIC COMPLICATIONS IN 3RD TRIMESTER
}

1. MBBS, Postgraduate Trainee, Obs \& Gynae Department, $\mathrm{CMH}$, Multan

2. MBBS, MCPS, FCPS Head of Department Obs \& Gynae $\mathrm{CMH}$, Multan.

3. MBBS, Postgraduate Trainee, Obs \& Gynae Department, Nishtar Hospital, Multan

Correspondence Address: Dr. Shah Bano

MBBS, Postgraduate Trainee, Obs \& Gynae Department, $\mathrm{CMH}$, Multan.

Article received on:

10/02/2017

Accepted for publication:

$15 / 06 / 2017$

Received after proof reading: 08/09/2017

\begin{abstract}
Shah Bano', Shabnam Naseer Awan², Asma Rahman ${ }^{3}$
ABSTRACT... Objectives: The objective of this study was to determine the frequency of complications in pregnant women with fibroids in $3^{\text {rd }}$ trimester. Study design: Descriptive Case Series. Setting: Department of Obstetrics \& Gynecology, Nishtar Hospital, Multan. Period: $15^{\text {th }}$ December 2014 to $15^{\text {th }}$ June 2015. Subjects \& Methodology: Where sample size was calculated using WHO sample size calculator using expected proportion of intrauterine growth restriction $p=4 \% .{ }^{11} 163$ pregnant women of $20-40$ year of age with uterine fibroid of $\geq 3 \mathrm{~cm}$ on ultrasound were included in this study. Patients of endometriosis and hypertension were excluded. An obstetrical ultrasonography was done to confirm singleton pregnancy, size of uterine fibroid and to confirm gestational age. Patients were monitored until delivery and complications were recorded. Preterm labour was defined as dilation of the cervix $<4 \mathrm{~cm}$ with the presence of uterine contractions of $\geq 4$ per hour of 30 seconds duration with intensity to effect progressive effacement, assessed by vaginal examination. Malpresentation was defined as a presentation in which baby's bottom or feet, instead of head, are in position relative to the maternal pelvis by ultrasound and IUGR was defined as fetal weight below the 10th percentile and fetal abdominal circumference below the 10th percentile on ultrasound. Results: Age range in this study was from 20 to 40 years with mean age of $32.773 \pm 1.99$ years, mean gestational age $34.730 \pm 2.44$ weeks, fibroid size $5.736 \pm 1.51 \mathrm{~cm}$, duration of complain $5.018 \pm 1.41$ months, height $1.561 \pm 0.11$ meters, mean weight $73.619 \pm 13.66 \mathrm{Kg}$ and mean BMI was $28.607 \pm 3.106$ $\mathrm{Kg} / \mathrm{m}^{2}$. Majority of the patients were from 31-40 year group (89\%). Preterm labour was seen in $15.3 \%$ patients, malpresentation was $7.4 \%$ and IUGR was seen in $6.1 \%$ patients. Conclusion: Our study conclude that, most common complication of uterine fibroids during pregnancy was preterm labour followed by malpresentation and IUGR.
\end{abstract}

Key words: $\quad$ Fibroids, Pregnancy, Preterm labour, Malpresentation, Intrauterine growth restriction.

Article Citation: Bano S, Awan SN, Rahman A. Fibroid in pregnancy; obstetric complications in $3^{\text {rd }}$ trimester. Professional Med J 2017;24(9):1360-1364.

DOI: $10.17957 / T P M J / 17.3875$

\section{INTRODUCTION}

Fibroids are the most widely recognized estrogen subordinate benign tumors of the uterus happening in the women in child bearing age. Symptom less fibroids are found in half of cases. ${ }^{1}$ Due to pregnancy related hormones, fibroid can develop in size and experience red degeneration. Development of fibroid is reliant on estrogen generation and growth elements. ${ }^{2}$ Excessive estrogen discharge, particularly when continuous by pregnancy and lactation are thought to be the most vital risk for the advancement of fibroid. It develop fundamentally menstrual issues, for example, abnormal uterine bleeding and infertility. ${ }^{3}$ For the most part, pregnancy with fibroid continue without any hazard, yet sometime, they can influence the proceeding of pregnancy. ${ }^{4,5}$

Pregnant women with fibroids have high cesarean rates as compare to women without fibroids. ${ }^{8}$

The impacts of these fibroids on pregnancy are matter of concern especially due to their occurrence in child bearing age. ${ }^{9}$

Fibroids, particularly situated in the uterus, may develop the possibility of pregnancy complications. ${ }^{5}$ In initial trimesters, they may bring about red degeneration prompting to extreme pain in lower abdomen. ${ }^{6}$ They likewise develop the 
danger of intrauterine growth restriction, unusual implantation of placenta and malpresentation. ${ }^{7}$

Fibroids can cause a number of complications like miscarriage, $\mathrm{PPH}$, preterm delivery and placental abruption. ${ }^{10}$

Raja KS and his associates has found in a study that frequency of preterm labour was $10 \%$, malpresentation $4 \%$ and intrauterine growth restriction was $4 \%$ in pregnant women with fibroids in $3^{\text {rd }}$ trimester. ${ }^{11}$

Lee $\mathrm{HJ}$ and his associates has found in another study that frequency of preterm labour was $16.1 \%$, malpresentation $13 \%$ and intrauterine growth restriction was $11.2 \%$ in pregnant women with fibroids in $3^{\text {rd }}$ trimester. $^{12}$

In practice there is a paucity of data on frequency of complications in pregnant women with fibroids in our general population. So I have decided to determine the frequency of complications in pregnant women with fibroids in $3^{\text {rd }}$ trimester in our general population. My study will pave the way for our doctor community to improve the obstetric care to avoid the incidence of complications in pregnant women with fibroids.

\section{MATERIAL AND METHODS}

This descriptive case series was conducted in indoor Department of Obstetrics \& Gynecology, Nishtar Hospital, Multan from $15^{\text {th }}$ December 2014 to $15^{\text {th }}$ June 2015 . Where sample size was calculated using WHO sample size calculator using expected proportion of intrauterine growth restriction $p=4 \% .{ }^{11} 163$ pregnant women of 20 40 year of age with uterine fibroid of $\geq 3 \mathrm{~cm}$ on ultrasound were included in this study. Patients of endometriosis and hypertension were excluded.

Base line demographic information of patients (age, parity, gestational age, weight and duration of complaint (fibroid)) was taken. Informed consent was taken from each patient, ensuring confidentiality and fact that there is no risk involved to the patient while taking part in this study. An obstetrical ultrasonography was done to confirm single pregnancy, size of uterine fibroid and to confirm gestational age. Patients were monitored until delivery and complications were recorded. Preterm labour was defined as dilation of the cervix $<4 \mathrm{~cm}$ with the presence of uterine contractions of $\geq 4$ per hour of 30 seconds duration with intensity to effect progressive effacement, assessed by vaginal examination. A malpresentation was defined as a presentation in which baby's bottom or feet, instead of head, are in position relative to the maternal pelvis and it was determined by ultrasound and IUGR was defined as fetal weight below the 10th percentile and fetal abdominal circumference below the 10th percentile on ultrasound. Complications were treated as per protocol by consultant gynecologist.

Data was analyzed with statistical analysis program (SPSS version15). Frequency and percentage was computed for qualitative variables like age groups, gravida, parity, complications (preterm labour, malpresentation and intrauterine growth restriction). Mean $\pm S D$ was presented for quantitative variables like age, gestational age, Fibroid size, duration of complaint (fibroid), height, weight and BMI. Effect modifiers like Fibroid size and duration of complaint were controlled by stratification. Post stratification chi square test was applied to see the effect of these on outcome (complications) $p \leq 0.05$ was considered statistically significant.

\section{RESULTS}

Age range in this study was from 20 to 40 years with mean age of $32.773 \pm 1.99$ years, mean gestational age $34.730 \pm 2.44$ weeks, fibroid size $5.736 \pm 1.51 \mathrm{~cm}$, duration of complain $5.018 \pm 1.41$ months, height $1.561 \pm 0.11$ meters, mean weight $73.619 \pm 13.66 \mathrm{Kg}$ and mean $\mathrm{BMI}$ was $28.607 \pm 3.106 \mathrm{Kg} / \mathrm{m}^{2}$ as shown in Table-I.

Majority of the patients were from 31-40 year group (89\%) as shown in Table -II.

Preterm labour was seen in $15.3 \%$ patients, malpresentation was $7.4 \%$, IUGR was $6.1 \%$ patients as shown in Table-III.

Stratification of preterm labour, malpresentation 
and IUGR with respect to fibroid size are shown in Table-IV to VI respectively.

\begin{tabular}{|c|c|}
\hline Demographics & Mean \pm SD \\
\hline Age(years) & $32.773 \pm 1.99$ \\
\hline Gestational Age(weeks) & $34.730 \pm 2.44$ \\
\hline Fibroid Size $(\mathrm{cm})$ & $5.736 \pm 1.51$ \\
\hline Duration of complain (months) & $5.018 \pm 1.41$ \\
\hline Height (m) & $1.561 \pm 0.11$ \\
\hline Weight (Kg) & $73.619 \pm 13.66$ \\
\hline BMI (kg/m2) & $28.607 \pm 3.106$ \\
\hline \multicolumn{2}{|c|}{$\begin{array}{c}\text { Table-I. Mean } \pm \text { SD of patients according to age, } \\
\text { Gestational age, fibroid size, duration of complain, } \\
\text { height, weight and BMI } n=163\end{array}$} \\
\hline
\end{tabular}

\begin{tabular}{|c|c|c|}
\hline Age (Years) & No of Patients & $\%$ age \\
\hline $20-30$ & 18 & $11 \%$ \\
\hline $31-40$ & 145 & $89 \%$ \\
\hline Table-II. Frequency and percentage according to \\
age $n=163$
\end{tabular}

\begin{tabular}{|l|c|}
\hline \multicolumn{1}{|c|}{ Complications } & $\mathbf{n}(\%)$ \\
\hline Preterm Labour & $25(15.3 \%)$ \\
\hline Malpresentation & $12(7.4 \%)$ \\
\hline IUGR & $10(6.1 \%)$ \\
\hline \multicolumn{2}{|c|}{ Table-III. Frequency and percentage of } \\
complications $\mathrm{n}=163$
\end{tabular}

\begin{tabular}{|l|c|c|c|}
\hline & \multicolumn{2}{|c|}{ Preterm labour } & \multirow{2}{*}{ P value } \\
\cline { 1 - 2 } Fibroid Size(cm) & Yes & No & \\
\hline $3-5$ & $14(18.9 \%)$ & $60(81.1 \%)$ & \multirow{2}{*}{0.247} \\
\hline$>5$ & $11(12.4 \%)$ & $78(87.6 \%)$ & \\
\hline Total & $25(15.3 \%)$ & $138(84.7 \%)$ & \\
\hline
\end{tabular}

Table-IV. Stratification of Preterm labour with respect to fibroid size

\begin{tabular}{|l|c|c|c|}
\hline & \multicolumn{2}{|c|}{ Malpresentation } & \multirow{2}{*}{ P value } \\
\cline { 1 - 2 } Fibroid size (cm) & Yes & No & \\
\hline $3-5$ & $0(0 \%)$ & $74(100 \%)$ & \\
\hline$>5$ & $12(13.5 \%)$ & $77(86.5 \%)$ & \multirow{2}{*}{0.001} \\
\hline Total & $12(7.4 \%)$ & $151(92.6 \%)$ & \\
\hline
\end{tabular}

Table-V. Stratification of Malpresentation with respect to fibroid size

\begin{tabular}{|c|c|c|c|}
\hline \multirow[b]{2}{*}{ Fibroid size (cm) } & \multicolumn{2}{|c|}{ IUGR } & \multirow{2}{*}{$\begin{array}{c}P \\
\text { value }\end{array}$} \\
\hline & Yes & No & \\
\hline $3-5$ & $0(0 \%)$ & $74(100 \%)$ & \multirow{3}{*}{0.003} \\
\hline$>5$ & $10(11.2 \%)$ & $79(88.8 \%)$ & \\
\hline Total & $10(6.1 \%)$ & 153(93.9\%) & \\
\hline
\end{tabular}

Table-VI. Stratification of IUGR with respect to fibroid size

\section{DISCUSSION}

In our study preterm labour was seen in 15.3\% patients, malpresentation was $7.4 \%$, IUGR was $6.1 \%$ patients. These results are comparable with a study done by Raja KS and his associates who found the frequency of preterm labour by $10 \%$, malpresentation $4 \%$ and intrauterine growth restriction was $4 \%$ in pregnant women with fibroids in $3^{\text {rd }}$ trimester. ${ }^{11}$ Lee $\mathrm{HJ}$ and his associates has found in another study that frequency of preterm labour was $16.1 \%$, malpresentation $13 \%$ and intrauterine growth restriction was $11.2 \%$ in pregnant women with fibroids in $3^{\text {rd }}$ trimester. ${ }^{12}$

The mean maternal age in our study was 33 years which is similar to other studies. ${ }^{13}$ The relationship of uterine fibroid with previous zero parity has been reported ${ }^{14}$ however may happen in multiparous women with the equal percentage..$^{15}$ Small fibroid may have increment in size among $1^{\text {st }}$ and $2^{\text {nd }}$ trimester and decline in size amid the $3^{\text {rd }}$ trimester. ${ }^{16}$ While, large fibroids tend to increment in size in the $1^{\text {st }}$ trimester and abatement in size amid the $2^{\text {nd }}$ and the $3^{\text {rd }}$ trimesters, ${ }^{17}$ as fibroids are more receptive to the expanded centralizations of estrogen present in pregnancy. ${ }^{18}$ Progesterone then again may repress the development of fibroid and even suppress the growth of fibroid. ${ }^{19}$

In antenatal period, fibroid related morbidity found in $70 \%$ patients and $30 \%$ patients stayed without any symptoms, as revealed in a study. ${ }^{20}$ Our study additionally affirmed the finding of earlier reviews exhibiting that preterm labour rates were higher in women with myomas. ${ }^{21}$ Preterm labour might be created due to increased uterine peevishness, either due to quick development of myoma or its degeneration interfere with the typical pregnancy and its impact of the fibroid may modify the endometrium specifically and disturb the normal development procedure of the fetus. The compacted endometrial blood supply influences the fetus unfavorably bringing about abortion. ${ }^{22}$ Fibroid may twist the state of the uterine cavity which may represent higher rates of malpresentation and preterm birth. ${ }^{23}$ In pregnancy course, myometrium having myoma are over extended and this instrument can start 
work and along these lines result in expanded rate of preterm labour. ${ }^{24}$

\section{CONCLUSION}

Our study conclude that, most common complication of uterine fibroids during pregnancy was pretrm labour followed by malpresentation and IUGR.

Copyright(C) 15 June, 2017.

\section{REFERENCES}

1. Jothikala C, Hameed J, Radhika S, Haseena S, Nazar $M$. Lower uterine segment fibroid complicating pregnancy: a case report. Int J Sci Stud 2014; 1(6):1819.

2. Levy G, Hill MJ, Beall S, Zarek SM, Segars JH, Catherino WH. Leiomyoma: genetics, assisted reproduction, pregnancy and therapeutic advances. J Assist Reprod Genet 2012; 29:703-12.

3. Jayakrishnan K, Menon V, Nambiar D. Submucous fibroids and infertility: effect of hysteroscopic myomectomy and factors influencing outcome. J Hum Reprod Sci 2013; 6:35-9.

4. Coronda GD, Marshall LM, Schwartz SM. Complications in pregnancy, labour and delivery with uterine leiomyomas: a population based study. Obstet Gynecol 2000; 95:764-9.

5. Khan AT, Shehmar M, Gupta JK. Uterine fibroids: current perspectives. Int J Womens Health 2014; 6:95114.

6. Davis JL, Kay HH, Mazumder S, Habel CJ, Baley K, Sassoon D. Uterine leiomyomas in pregnancy: a prospective study. Obstet Gynecol 1990; 75:41-4.

7. Fleischer AC, Shah DM, Entmam SS. Sonographic evaluation of material disorders during pregnancy. Radiol Clin North Am 1990; 28:51-8.

8. Lefebure G, Vilos G, Allaire C, Jeffery J, Arneja J, Birsh $C$, et al. The management of uterine leiomyoma. Obstet Gynecol Can 2003; 25:396-418.

9. Qidwai GI, Caughey AB, Jacoby AF. Obstetric outcome in women with sonographically identified uterine leiomyomata obstetric. Obstet Gynecol 2006 Feb; 107(2 Pt 1):376-82.

10. Quyang DW, Economy KE, Norwitz ER. Obstetric complications of fibroids. Obstet Gynaecol Clin North Am 2006; 33(1):153-69.
11. Raja KS, Tasleem H. Effects of uterine leiomyoma on the course of pregnancy and labour. Rawal Med J 2009; 34(1):79-81.

12. Lee HJ, Norwitz ER, Shaw J. Contemporary management of fibroids in pregnancy. Rev Obstet Gynecol 2010; 3(1):20-27.

13. Marom D, Pitlik S, Sagie A, Ovadia Y, Bishara J. Uterine leiomyoma and pregnancy. Am J Obstet Gyncol 1998; 178:620-1.

14. Ashraf T. Management of uterine leiomyomas. J Coll Physicians Surg Pak 1997; 7:160-2.

15. Cesen C K, Copland JA, Barrett JC, Walker CL, Davis BJ. Pregnancy, parturition, and prostaglandins: defining uterine leiomyomas. Environ Health Prospect 2000; 5:817-20.

16. Woyton J, Tonialowicz M, Florjanski J. Uterine myomas in pregnancy. Ginecol Pol 2002; 73:301-6.

17. Katz VL, Dotters DJ, Droegemueller W. Complications of uterine leiomyomas in pregnancy. Obstet Gynecol 1989; 73:593.

18. Treissman DA, Bate JT, Randall PT. Epidural use of morphine in managing the plain of carneous degeneration of a uterine leiomyomas during pregnancy. J Can Med Assoc 1982; 126:505.

19. Wingo PA, Huezo CM, Rubin GL, Ory HW, Peterson HB. The mortality risk associated with hysterectomy for benign conditions of uterus. Am J Obstet Gynecol 1985; 152:803-7.

20. Monaghan JM. Myomectomy and management of fibroids in pregnancy. Bonney Gynecol Surg 1986:8795.

21. Ramzy AM, Sattar M, Amin Y. Uterine myomata and outcome of assisted reproduction. Hum Reprod 1998; 13:198-202.

22. Chuang J, Tsai HW, Hwang JL. Fetal compression syndrome caused by myoma in pregnancy. A case report. Acta Obstet Gynecol Scand 2001; 80:472-3.

23. Vergani P, Ghidini A, Strbelt N, Roncaglia N, Locatelli $\mathrm{A}$, Lapinski $\mathrm{RH}$, et al. Do uterine Leiomyma influence pregnancy outcome. Am J Perinatol 1994; 11:356-8.

24. Exacoustos C, Rosati P. Ultrasound diagnosis of uterine myomas and complications in pregnancy. Am J Obstet Gynecol 1993; 82:881-2. 


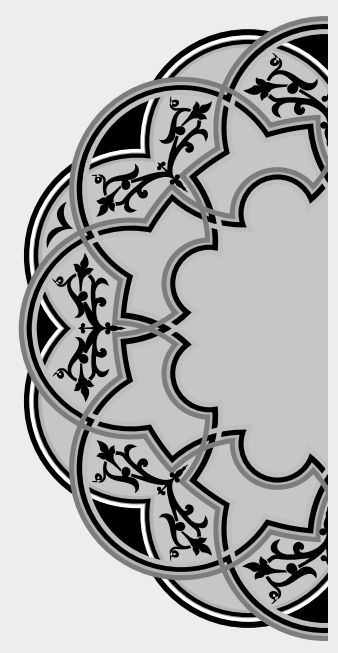

\title{
"The best preparation for tomorrow is doing your best today."
}

\author{
Jpseph Campbell
}

AUTHORSHIP AND CONTRIBUTION DECLARATION

\begin{tabular}{|c|l|l|l|}
\hline Sr. \# & \multicolumn{1}{|c|}{ Author-s Full Name } & \multicolumn{1}{|c|}{ Contribution to the paper } & Author=s Signature \\
\hline 1 & Shah Bano & 1st Author & \\
2 & Shabnam Naseer Awan & 2nd Author & 3rd Author \\
3 & Asma Rahman & &
\end{tabular}

